\title{
Gestational Diabetes and the Offspring: Implications in the Development of the Cardiorenal Metabolic Syndrome in Offspring
}

\author{
Liliana Garcia-Vargas $^{a}$ Sonya S. Addison ${ }^{a}$ Ravi Nistala ${ }^{b}$ \\ Damascene Kurukulasuriya $^{a}$ James R. Sowers ${ }^{a, c, d}$ \\ Divisions of a Endocrinology and ${ }^{\mathrm{b}}$ Nephrology, Department of Internal Medicine, and ${ }^{\mathrm{c}}$ Department of \\ Medical Pharmacology and Physiology, University of Missouri-Columbia, and ${ }^{\mathrm{d}}$ VA Medical Center, \\ Columbia, Mo., USA
}

\author{
Key Words \\ Gestational diabetes $\cdot$ Offspring $\cdot$ Fetal programming $\cdot$ Cardiorenal syndrome
}

\begin{abstract}
The risk of developing type 2 diabetes and cardiovascular disease in women who had previously been diagnosed with gestational diabetes (GDM) is well established. There is increasing evidence that the offspring of women with GDM are at increased risk for the development of all components of the cardiorenal metabolic syndrome. Overall, it appears that these offspring have an increased risk for overweight/obesity, insulin resistance, higher blood pressure, renal disease, and type 2 diabetes. However, distinct differences in regional populations, lack of routine screening and treatment of GDM worldwide, and long follow-up periods for offspring represent a challenge in assessing the risk for development of these abnormalities in the offspring of women who have had GDM.

Copyright $\odot 2012$ S. Karger AG, Basel
\end{abstract}

\section{Introduction}

According to the World Health Organization, in 2008 more than 1 in 10 of the world's adult population was obese, and by 2015 approximately 2.3 billion adults will be overweight and $>700$ million will be obese [1]. A major concern for the future is the growing prevalence 


\section{CardioRenal Medicine}

\begin{tabular}{l|l}
\hline Cardiorenal Med 2012;2:134-142 \\
\hline DOI: 10.1159/000337734 & $\begin{array}{l}\text { @ 2012 S. Karger AG, Basel } \\
\text { www.karger.com/crm }\end{array}$ \\
Published online: April 12, 2012 &
\end{tabular}

Garcia-Vargas et al.: GDM and the Offspring: Development of the CRS

of this problem in young people. In 2010, approximately 45 million children under 5 years of age were overweight, and according to the data from the National Health and Nutrition Examination Survey (NHANES), the prevalence of obesity in adolescents increased from 5\% in 1999 to 17\% in 2006. Prevalence among Mexican American, African American and nonHispanic Black adolescents is particularly disturbing [2].

Obesity-related health conditions such as cardiovascular disease, chronic kidney disease, and type 2 diabetes mellitus are increasing in parallel with the obesity pandemic. The prevalence of the cardiorenal metabolic syndrome (CRS) in adolescents is approximately $4 \%$ and close to $30 \%$ in adolescents with a body mass index (BMI) above the 95th percentile [3]. Obesity-associated diseases of middle age such as steatohepatitis, sleep apnea, type 2 diabetes, and hypertension are now increasingly seen in adolescents.

Overnutrition and a sedentary lifestyle are widely recognized as contributory to childhood and adolescent obesity. Observational studies have identified intrauterine hyperglycemia as an important predictor of BMI, insulin resistance, and hypertension in children and adolescents (fig. 1) [4].

During pregnancy, fetal growth and development obligates an increasing maternal-tofetal glucose supply. As a consequence, the mother develops a state of insulin resistance in order to guarantee a positive maternal-fetal gradient of glucose. During the first trimester and at the beginning of the second trimester of pregnancy, insulin resistance does not substantively change. In response to increasing placental mammasomatotropin, after the midway point of the second trimester, the requirement for insulin increases by 2.0 - to 2.5 -fold in order to maintain a state of maternal euglycemia [5]. Gestational diabetes (GDM) occurs when maximal insulin secretion cannot match the degree of insulin resistance. When this occurs, mother and fetus are both exposed to hyperglycemia. Hyperglycemia in pregnancy has detrimental effects on both mother and fetus, including hypertension, pre-eclampsia, increased need for premature operative delivery, macrosomia, fetal trauma, low Apgar score, and fetal hypoglycemia. 'Gestational programming' in the fetus may predispose to future diseases such as obesity, hypertension, renal disease, and diabetes [6].

This review will summarize current concepts of gestational programming, its pathophysiology and clinical consequences, which lessen these risks.

\section{GDM Predisposes to Development of Hypertension in Offspring}

Studies of the relationship between maternal GDM and blood pressure in offspring have been mixed. The Jerusalem perinatal study was a large cohort of $>60,000$ singleton births from 1964 and 1976. Women with GDM were identified and their children were evaluated at the age of 17 years for several characteristics, including blood pressure. No significant link between GDM and systolic blood pressure was found. However, offspring of mothers with higher pre-pregnancy BMIs were more likely to have higher diastolic blood pressure (DBP), suggesting a stronger link between BMI and DBP than GDM and DBP [7]. In contrast, in a retrospective study in Pima Indians, systolic blood pressure in children aged 7-11 years was significantly increased in the offspring of women with GDM [8]. This relationship remained significant even when adjusted for birth weight or childhood adiposity. In a third study, the systolic and mean arterial blood pressure was significantly higher in the children of mothers with GDM, even when adjusted for higher maternal BMI [9]. 


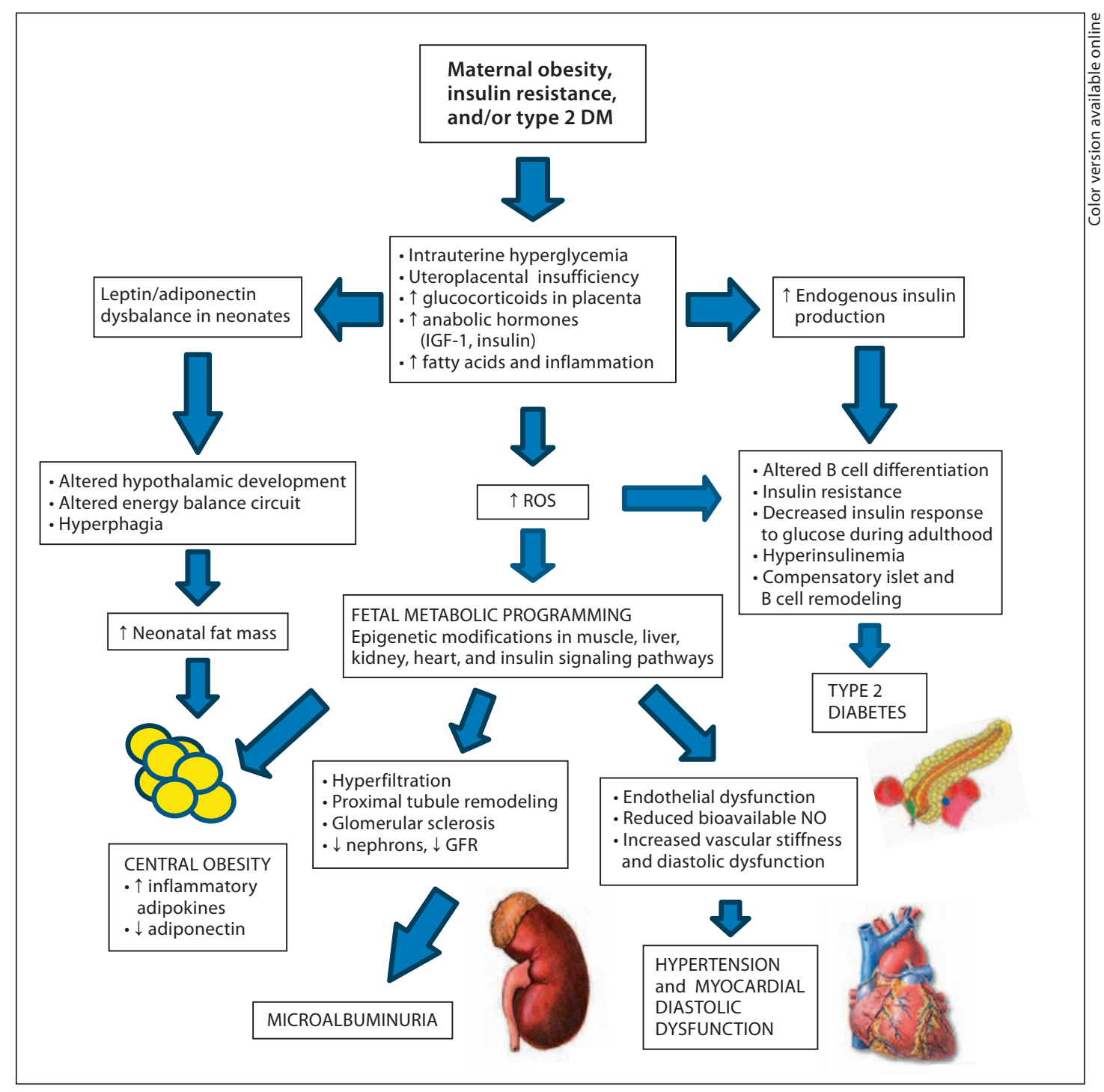

Fig. 1. Maternal GDM and associated CRS in offspring. The imbalance in the levels of leptin/adiponectin in the neonate of a mother with GDM affects the neurodevelopment of appetite centers in the hypothalamus causing hyperphagia. Diabetes during gestation causes an inflammatory response at the level of the placenta. The ROS generated in the maternal-fetal placenta microenvironment can induce inhibitory or permissive gene expression resulting in chromatin epigenetic remodeling of genes in multiple organs including the pancreas, kidney, heart, and muscle. The future development of the CRS is mediated by these modifications in the transcriptome and the presence of persistent stressors in the future life of the offspring. $\mathrm{ROS}=$ Radicals of oxygen species; $\mathrm{NO}=$ nitric oxide.

\section{Overweight and Obesity in Offspring}

Offspring of mothers with GDM are at increased risk for excessive BMI. A study in the UK examined the relationship between GDM and overweight/obesity in adolescent offspring, ages 9-11 years, demonstrating an increased risk with maternal GDM (but not pre-existing type 2 diabetes mellitus) [10]. During adolescence, the risk of overweight and obesity was also higher in the progeny of women with GDM. By age 17 years, a higher BMI was also significantly as- 


\section{CardioRenal Medicine}

\begin{tabular}{l|l}
\hline Cardiorenal Med 2012;2:134-142 \\
\hline DOI: 10.1159/000337734 & $\begin{array}{l}\text { @ 2012 S. Karger AG, Basel } \\
\text { www.karger.com/crm }\end{array}$ \\
Published online: April 12, 2012 &
\end{tabular}

Garcia-Vargas et al.: GDM and the Offspring: Development of the CRS

sociated with GDM [7]. A prospective cohort study of $>280,000$ men found that the trend of obesity in the offspring of women with GDM continues to be seen into early adulthood [11].

From available data, it can be concluded that overweight/obesity and maternal weight gain during pregnancy are not only risk factors for GDM, but for overweight and obesity in offspring [12]. Independent of GDM, obese women and those with excessive weight gain in pregnancy are more likely to have obese offspring [13]. Offspring of obese mothers are also at higher risk of developing cardiovascular disease, fatty liver disease, renal disease, and impaired glucose intolerance and type 2 diabetes [14].

\section{Type 2 Diabetes in Offspring}

It is well established that women with GDM have an increased risk of developing type 2 diabetes mellitus [15]. Several groups have investigated the relationship between type 2 diabetes in offspring and their mothers who had GDM. Studies are difficult to compare due to differences in screening for GDM and treating GDM worldwide, and due to different ethnicity-linked genetic factors and environmental exposures.

A study in Pima Indians (a known high-risk population for type 2 diabetes) investigated the relationship between intrauterine hyperglycemia and later development of type 2 diabetes in offspring [16]. The researchers evaluated sibling pairs in which one sibling was born prior to and one born after the maternal diagnosis of type 2 diabetes. They concluded that the siblings born after the diagnosis (hence hyperglycemia during gestation) were at higher risk for developing type 2 diabetes and obesity than the siblings exposed to normoglycemic intrauterine conditions [16]. This suggests that maternal hyperglycemia is one factor driving the development of diabetes in children of women with GDM (fig. 1).

Another Pima Indian study examined the effect of impaired glucose tolerance in the third trimester of pregnancy [17]. Young adults who were born to mothers with impaired glucose tolerance in pregnancy (blood glucose $140-200 \mathrm{mg} / \mathrm{dl} 2 \mathrm{~h}$ following 75 -gram oral glucose challenge) were at a significantly higher risk of developing type 2 diabetes. At age 20 years, the cumulative risk of type 2 diabetes in the offspring was approximately $15 \%$, with an increase to about $30 \%$ at age 24 years. The degree of hyperglycemia after glucose challenge in the third trimester correlated directly with the risk of type 2 diabetes in offspring. Those who were born to mothers with known type 2 diabetes had the highest risk (51\%) at 24 years, while those whose mothers displayed normoglycemia had an $8 \%$ risk at 24 years. In a Danish study, the offspring of women with GDM had an 8-fold increased risk of diabetes/pre-diabetes due to any diagnosis - ranging from GDM to pre-existent type 1 diabetes [18]. Data from this study also indicated that intrauterine hyperglycemia, whether the mother is known to have type 1 diabetes or GDM, is associated with type 2 diabetes and/or pre-diabetes in adult offspring. At age 22 years, the prevalence of type 2 diabetes/pre-diabetes was $21 \%$ in the offspring of mothers with GDM, $11 \%$ in those whose mothers had pre-gestational type 1 diabetes, and $4 \%$ in the offspring of mothers with no diabetes. For mothers with type 1 diabetes, hyperglycemia in the third trimester was associated with an increased diabetes risk in their offspring [18].

\section{Possible Mechanisms Involved in the 'Gestational Transmission' of Diabetes, Obesity, and Cardiometabolic Disease to the Offspring of GDM Mothers}

Based on available data, it can be concluded that GDM is a risk factor for type 2 diabetes and CRS in the offspring. These results gave rise to the hypothesis that there is a form of 'gestational transmission' of diabetes and the CRS. Pathophysiology may include epigenetic 


\section{CardioRenal Medicine}

\begin{tabular}{l|l}
\hline Cardiorenal Med 2012;2:134-142 \\
\hline DOI: 10.1159/000337734 & $\begin{array}{l}\text { @ 2012 S. Karger AG, Basel } \\
\text { www.karger.com/crm }\end{array}$ \\
\hline Published online: April 12, 2012
\end{tabular}

Garcia-Vargas et al.: GDM and the Offspring: Development of the CRS

modifications and the disarrangement in the balance between glucose, insulin, and other regulatory hormones involved in glucose homeostasis during the intrauterine and perinatal life [19]. Animal models have yielded evidence toward both intrauterine metabolic and epigenetic factors. Human studies are largely lacking.

\section{Role of Epigenetic Mechanisms}

Epigenetic mechanisms involve changes in gene expression without a change in the nucleotide sequence [20]. These include DNA methylation, post-translational histone modifications, and non-coding RNA-mediated silencing processes that can be transmitted from one cell generation to the next (mitotic inheritance) or be transmitted through generations (meiotic inheritance) $[19,20]$. Environmental stressors can induce epigenetic changes, with a subsequent effect on phenotype which can be transmitted to the offspring. The hypothesis that fetal exposure to a detrimental environment such as intrauterine hyperglycemia and uteroplacental insufficiency causes an increased risk of developing impaired glucose tolerance or diabetes via epigenetic mechanisms was first postulated by Barker [4]. This hypothesis is supported by the recent advances elucidating potential target genes involved in the pathogenesis of diabetes such as the pancreatic homeobox transcription factor Pdx-1 involved in the differentiation of pancreatic $\beta$ cells and the understanding that gene expression relies on a complex interaction between DNA and transcription factors, the link between environmental factor, and epigenetic modifications.

Intrauterine growth retardation (IUGR) and/or low birth weight followed by accelerated growth and weight gain in infancy and childhood are associated with an increased risk of insulin resistance, obesity, diabetes, renal, and cardiovascular disease [19, 21, 22]. The oxidative stress and altered metabolic microenvironment related to the uteroplacental insufficiency may be responsible for modifications in the chromatin regulation and eventual transcription of important genes involved in the development of diabetes. It has been reported that $\mathrm{Pdx}-1$ expression was reduced in a rodent model with IUGR [23]. Investigators were able to decode the epigenetic modifications involved in the cascade of events that concluded in a silent transcription of this important gene during adulthood causing diabetes. $\mathrm{Pdx}-1$ is a pancreatic and duodenal homeobox 1 transcription factor that regulates pancreas development and $\beta$ cell differentiation. Pdx- 1 was first described in the pathogenesis of the monogenic form of diabetes MODY 4. The cascade of events starting during intrauterine life through adulthood starts with a loss of USF-1 binding at the proximal promoter of Pdx-1, recruitment of histone deacetylases 1 (HDAC1) and the co-repressor Sin 3A, and deacetylation of $\mathrm{H} 3$ and H4. After birth, histone 3 lysine 4 (H3K4) was demethylated and histone 3 lysine 9 (H3K9) was methylated. As a consequence, there is increased methylation in the CpG island proximal promoter of the Pdx-1 with a subsequent blunting of its transcription and development of diabetes during adulthood. Interestingly, these changes were reversible in rodents exposed to the antagonist of the HDAC1 only during the neonatal life [23]. GDM has not been associated with the IUGR commonly seen in mothers with diabetes pre-dating pregnancy. However, hyperglycemia and the pro-inflammatory state associated with GDM may increase oxidative stress in the utero-placental-fetal unit. In this case, both conditions, GDM and uteroplacental insufficiency, may share the same cascade of transcriptome events seen in the animal model and potentially explain a mechanism for fetal programming.

A recent study in humans demonstrated an association between the percentage of DNA methylation of the leptin gene in the placenta and glycemia in the 2-hour post oral glucose tolerance test (OGTT) performed at 24-28 weeks of pregnancy. In the same study, the percentage of DNA methylation in the placenta was inversely correlated with the mother's mRNA levels in the placenta and serum leptin levels. The correlation of DNA methylation of the leptin gene and the expression of leptin mRNA in the placenta and serum leptin in the 


\section{CardioRenal Medicine}

\begin{tabular}{|c|c|}
\hline Cardiorenal Med 2012;2:134-142 & \\
\hline $\begin{array}{l}\text { DOI: 10.1159/000337734 } \\
\text { Published online: April 12, } 2012\end{array}$ & $\begin{array}{l}\text { (0) } 2012 \text { S. Karger AG, Basel } \\
\text { www.karger.com/crm }\end{array}$ \\
\hline
\end{tabular}

mother is in conflict with previous observations [5]. Nevertheless, this is the first study in humans that supports epigenetic modifications related to hyperglycemia in pregnancy [24]. Moreover, the significance of these epigenetic changes for future offspring is uncertain and may be an area of interest for future research.

\section{Disarrangement of the Maternal-Fetal Adipoinsular Axis during GDM and the}

Development of CRS and Diabetes in Offspring

The role of adipocytokines such as leptin, adiponectin, adipocyte fatty acid-binding protein (AFABP), and retinol-binding protein 4 (RBP4) in maintaining this balance of glucose between the mother and the fetus is still unclear, but animal model studies suggest that adipocytokines modulate the secretion of insulin in the maternal-fetal unit [25]. In GDM, an imbalance in the interplay between these adipocytokines and insulin secretion seems to be one of the reasons for the augmented insulin resistance in this disease.

Disarrangement of the adipoinsular axis during pregnancy may cause an excessive efflux of fuels through the placenta. The excess fuel supply may not only be teratogenic to the fetus, but may convey an increased risk for metabolic disorders far downstream in adulthood. This idea has arisen from observational studies that report hyperglycemia in GDM is an independent risk factor for obesity and diabetes in the offspring [26, 27]. Fetal adaptations to the increased concentration of glucose, amino acids, and lipids result in an excessive endogenous production of insulin and hyperplasia of $\beta$ cells in the pancreas. Other anabolic hormones, such as insulin growth factor-1 (IGF-1), have been found to be elevated in the placenta of mothers with GDM [28]. In GDM, fetal growth is regulated by interactions between the nutritional status and anabolic hormones that seem to be responsible for macrosomia and adiposity in the fetus. The effects of excessive nutrients associated with anabolic and growth properties may be associated with potential permanent damage in the fetal pancreas during a vulnerable 'window' of development with consequences that cannot be notorious until adult life [29]. In a rodent model of maternal diet-induced obesity with glucose intolerance and insulin resistance, the adult offspring developed glucose intolerance, hyperphagia, and fat accumulation. In the liver, altered expression of key components of the insulin signaling pathways occurred. The expression of insulin receptor substrate-1 (IRS-1) protein was decreased while phosphorylation of IRS-1 at Ser 307, an inhibitory signal of insulin action, was increased. These changes are key factors in the development of insulin resistance [30]. More fascinating is the notion that fetal hyperinsulinemia can cause permanent damage in the development of neuronal hypothalamic networks essential for energy balance and appetite [31]. Extrapolation of this finding in humans is more challenging considering that the fetal programming may differ between species.

Multiple attempts have been made to characterize the balance of leptin and adiponectin during pregnancies complicated with GDM. These two peptides are the most important orexigenic and anorexigenic hormones produced by the adipose tissue that control appetite, energy balance, and lipolysis. Leptin, for example, increases progressively through the pregnancy and reaches its peak at weeks 28-30. By the end of pregnancy, serum leptin can be as high as $2-3$ times the level in non-pregnant conditions, and after delivery this concentration drops to reach the non-pregnancy values by 6 weeks postpartum [32]. Investigators have demonstrated that leptin in the cord blood is also elevated, correlating with birth weight and fetal adipose tissue mass. However, maternal serum leptin is significantly higher and does not have a correlation with the umbilical cord levels [33]. This finding suggests that leptin in the umbilical cord originates and reflects the fetal nutrition status. In GDM, the leptin data are even more interesting: leptin levels in the cord serum of neonates are increased in comparison to controls [25]. The same observations have been reproduced in studies with ewes, where leptin mRNA from fetal adipose tissue was positively correlated with hyperinsu- 


\section{CardioRenal Medicine}

\begin{tabular}{l|l}
\hline Cardiorenal Med 2012;2:134-142 \\
\hline DOI: 10.1159/000337734 & $\begin{array}{l}\text { @ 2012 S. Karger AG, Basel } \\
\text { www.karger.com/crm }\end{array}$ \\
\hline Published online: April 12, 2012
\end{tabular}

Garcia-Vargas et al.: GDM and the Offspring: Development of the CRS

linemia [34]. On the other hand, the results of maternal leptin in this condition are contradictory as the majority of studies demonstrate an increase in serum leptin in comparison to mothers with normal OGTT. These differences in results are not well understood and may represent differences in ethnicity, BMI, or age between the groups $[5,35]$.

Adiponectin, a protein exclusively produced in the adipocyte and considered an insulinsensitizing, anti-inflammatory, and anti-atherogenic adipokine, was found to be lower in the maternal serum of mothers with GDM and mothers with normal oral OGTT in comparison to the level in cord blood, respectively. In the same study, Ortega-Senovilla et al. [25] demonstrated that maternal serum adiponectin in GDM was decreased $(\mathrm{p}<0.001)$ in comparison to the control group. They also observed a similar decrease in adiponectin in the cord blood of mothers with GDM when compared to the control group [25]. The role of adiponectin in pregnancy is unclear. Moreover, in healthy adults, adiponectin increases the insulin sensitivity in periphery tissues and acts as a starvation signal. The decreased levels in mothers and fetuses exposed to GDM may imply a decrease in anorexigenic messages to the hypothalamus and an increase in insulin resistance. There is not sufficient evidence that abnormalities of adiponectin levels will affect the newborn in adulthood. It is even less clear if low adiponectin during the fetal life can be related to the development of diabetes in the future.

\section{Diagnosis and Treatment of GDM}

In recent years, the screening and diagnostic criteria for GDM have changed. The ADA position statement published in January 2011 recommends that all women known to have diabetes should undergo a screening test with a 75-gram OGTT during weeks 24-28 of gestation. The diagnosis of GDM is made if any of the following plasma glucose values are exceeded: fasting $>92 \mathrm{mg} / \mathrm{dl}(5.1 \mathrm{mmol} / \mathrm{l}), 1 \mathrm{~h}>180 \mathrm{mg} / \mathrm{dl}(10 \mathrm{mmol} / \mathrm{l}), 2 \mathrm{~h}>153 \mathrm{mg} / \mathrm{dl}(8.5$ $\mathrm{mmol} / \mathrm{l})[36]$.

Current guidelines recommend strict glycemic control for GDM. Fasting blood sugar should be $<90 \mathrm{mg} / \mathrm{dl}$ and $<120 \mathrm{mg} / \mathrm{dl} 2 \mathrm{~h}$ postprandial. Diet and exercise are the main pillars in the treatment of GDM. The drug of choice in GDM is insulin. Treatment must manage hyperglycemia without causing hypoglycemia or compromising fetal nutrition.

Hyperglycemia is a known teratogen with effects ranging from preterm labor and preeclampsia in the mother to macrosomia, neonatal hyper- and/or hypoglycemia, dystocia of the shoulder at delivery, or congenital anomalies in the infant. The Australian Carbohydrate Oral Intolerance Study (ACHOIS) in pregnant women concluded that dietary and drug therapy reduces morbidity in the infant and improves health-related quality of life in women [37]. Multiple daily injections have been the mainstay for treatment, and achieving euglycemia is known to reduce the risk of complications for both mother and infant. Few drug studies have been performed in this population, and most evidence is observational. Insulin pumps are becoming a popular treatment modality, but studies have yet to prove that they are superior to multiple daily injections [38].

Newborns of mothers with GDM have an increase in fat mass which may be due to overnutrition (hyperglycemia) during pregnancy. Added fat mass may then lead to insulin and leptin resistance in these infants [39]. One group compared treatment of GDM with metformin or with insulin by looking at the body composition of the offspring at 2 years of age [40]. The children in the metformin group had larger upper arm and subscapular skin fold thickness, as well as larger upper arm circumference. Glucose control in the mothers during pregnancy was the same, as were baseline characteristics. Overall, the percentage of body fat, central-to-peripheral fat, and other measures were the same in both groups. The authors hypothesized that metformin treatment may have led to more subcutaneous fat deposition, 


\section{CardioRenal Medicine}

\begin{tabular}{l|l}
\hline Cardiorenal Med 2012;2:134-142 \\
\hline $\begin{array}{l}\text { DOI: 10.1159/000337734 } \\
\text { Published online: April 12, } 2012\end{array}$ & $\begin{array}{l}\text { @ 2012 S. Karger AG, Basel } \\
\text { www.karger.com/crm }\end{array}$ \\
\hline
\end{tabular}

which is more favorable than visceral fat on various CRS components. Further investigation is needed to determine visceral fat deposition and associated risk, and to determine if metformin should be a mainstay of treatment.

The maternal diet has also been implicated in the development of the offspring. It is suggested that the quality of carbohydrates consumed during pregnancy may affect outcome in the offspring. Mothers with insulin resistance and GDM may be able to decrease their insulin resistance and improve glucose tolerance by eating more whole grains and fiber as opposed to a more Western diet consisting of simpler carbohydrates and fatty foods [41]. A meta-analysis has shown that a low glycemic-index diet during pregnancy lowers the risk for macrosomia at birth and lowers adiposity measurements at birth, but overall, was inconclusive in other outcomes for the offspring [12]. Decreasing intrauterine hyperglycemia may be beneficial to the metabolic profile of the offspring later in life, but more studies are needed.

\section{References}

1 WHO fact sheet No. 311. Obesity and Overweight. September 2006. www.who.int/mediacentre/factsheets/fs311 (accessed December 8, 2011).

2 Ogden CL, Carroll MD, Flegal KM: High body mass index for age among US children and adolescents, 2003-2006. JAMA 2008;299:2401-2405.

-3 Cook S, Weitzman M, Auinger P, Nguyen M, Dietz W: Prevalence of a metabolic syndrome phenotype in adolescents: findings from the third National Health and Nutrition Examination Survey, 1988-1994. Arch Pediatr Adolesc Med 2003; 157:821.

4 Barker DJ: The fetal and infant origins of disease. Eur J Clin Invest 1995;25:457-463.

5 Miehle K, Stephan H, Fasshauer M: Leptin, adiponectin, and other adipokines in gestational diabetes mellitus and preeclampsia. Clin Endocrinol 2012;76:2-11.

66 Catalano PM, Kirwan JP, Haugel-de Mouzon S, King J: Gestational diabetes and insulin resistance: role in short- and long-term implications for mother and fetus. J Nutr 2003;133(5 suppl 2):1674S-1683S.

7 Tsadok MA, Friedlander Y, Paltiel O, Manor O, Meiner V, Hochner H, Sagy Y, Sharon N, Yazdgerdi S, Sisovick D, Elchalal U: Obesity and blood pressure in 17-year-old offspring of mothers with gestational diabetes: insights from the Jerusalem perinatal study. Exp Diabetes Res 2011;2011:906154.

8 Bunt JC, Tataranni PA, Salbe AD: Intrauterine exposure to diabetes is a determinant of hemoglobin Alc and systolic blood pressure in Pima Indian children. J Clin Endocrinol Metab 2005;90:3225-3229.

-9 Cho NH, Silverman BL, Rizzo TA, Metzger BE: Correlations between the intrauterine metabolic environment and blood pressure in adolescent offspring of diabetic mothers. J Pediatr 2000;136:587-592.

10 Lawlor DA, Fraser A, Lindsay RS, Ness A, Dabelea D, Catalano P, Smith GD, Sattar N, Nelson SM: Association of existing diabetes, gestational diabetes and glycosuria in pregnancy with macrosomia and offspring body mass index, waist and fat mass in later childhood: findings from a prospective pregnancy cohort. Diabetologia 2010;53:89-97.

11 Lawlor DA, Lichtenstein P, Langstrom N: Association of maternal diabetes mellitus in pregnancy with offspring adiposity into early adulthood: sibling study in a prospective cohort of 280,866 men from 248,293 families. Circulation 2011;123:258-265.

12 Petry CL: Gestational diabetes: risk factors and recent advances in its genetics and treatment. Br J Nutr 2010;104: 775-787.

13 Reynolds RM, Osmond C, Phillips DIW, Godfrey KM: Maternal BMI, parity, and pregnancy weight gain: influences on offspring adiposity in young adulthood. J Clin Endocrinol Metab 2010;95:5365-5369.

14 Drake AJ, Reynolds RM: Impact of maternal obesity on offspring obesity and cardiometabolic disease risk. Reproduction 2010;140:387-398.

15 Bellamy L, Casas JP, Hingoranie AD, Williams D: Type 2 diabetes after gestational diabetes: a systematic review and meta-analysis. Lancet 2009;373:1773-1779.

16 Dabelea D, Hanson RL, Lindsay RS, Pettitt DJ, Imperatore G, Gabir MM, Roumain J, Bennett PH, Knowler WC: Intrauterine exposure to diabetes conveys risks for type 2 diabetes and obesity. Diabetes 2000;49:2208-2211.

17 Franks PW, Looker HC, Kobes S, Touger L, Tataranni PA, Hanson RL, Knowler WC: Gestational glucose tolerance and risk of type 2 diabetes in young Pima Indian offspring. Diabetes 2006;55:460-465.

18 Clausen TD, Mathiesen ER, Hansen T, Pedersen O, Jensen DM, Lauenborg J, Damm P: High prevalence of type 2 diabetes and pre-diabetes in adult offspring of women with gestational diabetes mellitus or type 1 diabetes: the role of intrauterine hyperglycemia. Diabetes Care 2008;31:340-346.

19 Nistala R, Hayden MR, DeMarco V, Henriksen E, Lackland D, Sowers J: Prenatal programing and epigenetics in the genesis of the cardiorenal syndrome. Cardiorenal Med 2011;1:243-254. 


\section{CardioRenal Medicine}

\begin{tabular}{l|l}
\hline Cardiorenal Med 2012;2:134-142 \\
\hline DOI: 10.1159/000337734 & $\begin{array}{l}\text { @ 2012 S. Karger AG, Basel } \\
\text { www.karger.com/crm }\end{array}$ \\
Published online: April 12, 2012
\end{tabular}

Garcia-Vargas et al.: GDM and the Offspring: Development of the CRS

20 Fernandez-Morera JL, Rodriguez-Rodero S, Menendez-Torre E, Fraga MF: The possible role of epigenetics in gestational diabetes: cause, consequence or both. Obstet Gynecol Int 2010;2010:605163.

-21 Gluckman PD, Hanson Ma, Buklijas T, Low FM, Beedle AS: Epigenetic mechanisms that underpin metabolic and cardiovascular diseases. Nat Rev Endocrinol 2009;5:401-408.

22 Ozanne SE, Hales CN: Lifespan: catch-up growth and obesity in male mice. Nature 2004;427:411-412.

23 Park JH, Stoffers DA, Nicholls RD, Simmons RA: Development of type 2 diabetes following intrauterine growth retardation in rats is associated with progressive epigenetic silencing of Pdx1. J Clin Invest 2008;118:2316-2324.

24 Bouchard L, Thibault S, Guay SP, Santure M, Monpetit A, St-Pierre J, Perron P, Brisson D: Leptin gene epigenetic adaptation to impaired glucose metabolism during pregnancy. Diabetes Care 2010;33:2436-2441.

-25 Ortega-Senovilla H, Shaefer-Graf U, Meitzner K, Abou-Dakn M, Graf K, Kintscher U, Herrera E: Gestational diabetes mellitus causes changes in the concentrations of adipocyte fatty acid-binding protein and other adipocytokines in cord blood. Diabetes Care 2011;34:2061-2066.

26 Pettit DJ, Knowler WC: Long term effects of the intrauterine environment, birth weight and breast feeding in Pima Indians. Diabetes Care 1998;21:B138-B141.

27 Pettit DJ, Knowler WC, Bennett PH, Aleck KA, Baird HR: Obesity in offspring of diabetic Pima Indian women despite normal birth weight. Diabetes Care 1987;10:76-80.

28 Grissa O, Yessoufou A, Mrisak I, Hichami A, Amoussou-Guenou D, Grissa A, Djrolo F, Moutairou K, Miled A, Khairi H, Zaouali M, Bougmiza I, Zbidi A, Tabka Z, Khan NA: Growth factor concentrations and their placental mRNA expression are modulated in gestational diabetes mellitus: possible interactions with macrosomia. BMC Pregnancy Childbirth 2010;10:7.

29 Poston L: Developmental programming and diabetes - the human experience and insight from animal models. Best Pract Res Clin Endocrinol Metab 2010;24:541-552.

- 30 Samuelsson AM, Matthews PA, Argenton M, Christie MR, McConnell JM, Jansen EH, Piersma AH, Ozanne SE, Twinn DF, Remacle C, Rowlerson A, Poston L, Taylor PD: Diet induced obesity in female mice leads to offspring hyperphagia, adiposity, hypertension, and insulin resistance: a novel murine model of developmental programming. Hypertension 2008;51:383-392.

-31 Plagemann A, Harder T, Janert U, Rake A, Rittel F, Rohde W, Dörner G: Malformations of hypothalamic nuclei in hyperinsulinemic offspring of rats with gestational diabetes. Dev Neurosci 1999;21:58-67.

-32 Schubring C, Englaro P, Siebler T, Blum WF, Demirakca T, Kratzsch J, Kiess W: Longitudinal analysis of the maternal serum leptin levels during pregnancy, at birth and up to six weeks after birth: relation to body mass index, skinfolds, sex steroids and umbilical cord blood leptin levels. Horm Res1998;50:276-283.

-33 Schubring C, Kiess W, Englaro P, Rascher W, Dötsch J, Hanitsch S, Attanasio A, Blum WF: Levels of leptin in maternal serum, amniotic fluid, and arterial and venous cord blood: relation to neonatal and placental weight. J Clin Endocrinol Metab 1997;82:1480-1483.

34 Forhead AJ, Fowden AL: The hungry fetus? Role of leptin as a nutritional signal before birth. J Pysiol 2009;587:11451152.

- 35 Pirc LK, Owens JA, Crowther CA, Willson K, De Blasio MJ, Robinson JS: Mild gestational diabetes in pregnancy and the adipoinsular axis in babies born to mothers in the ACHOIS randomized control trial. BMC Pediatr 2007;7:18.

-36 American Diabetes Association: Diagnosis and classification of diabetes mellitus. Diabetes Care 2011;34:S62-S69.

37 Crowther C, Hiller J, Moss J, McPhee A, Jeffries W, Robinson J: Australian Carbohydrate Intolerance Study in Pregnant Women (ACHOIS) Trial Group. N Engl J Med 2005;352:2477-2486.

38 Castorino K, Paband R, Zisser H, Jovanovic L: Insulin pumps in pregnancy: using technology to achieve normoglycemia in women with diabetes. Curr Diab Rep 2012;12:53-59.

-39 Ali AT, Ferris WF, Naran NH, Crowther NJ: Insulin resistance in the control of body fat distribution: a new hypothesis. Horm Metab Res 2011;43:77-80.

40 Rowan JA, Rush EC, Obolonkin V, Batting M, Wouldes T, Hauge WM: Metformin in gestational diabetes: the offspring follow-up (MiG FOFU): body composition at 2 years of age. Diabetes Care 2011;34:2279-2284.

41 Tzanetakou IP, Mikhailidis DP, Perrea DN: Nutrition during pregnancy and the effect of carbohydrates on the offspring's metabolic profile: in search of the perfect maternal diet. Open Cardiovasc Med J 2011;5:103-109. 